
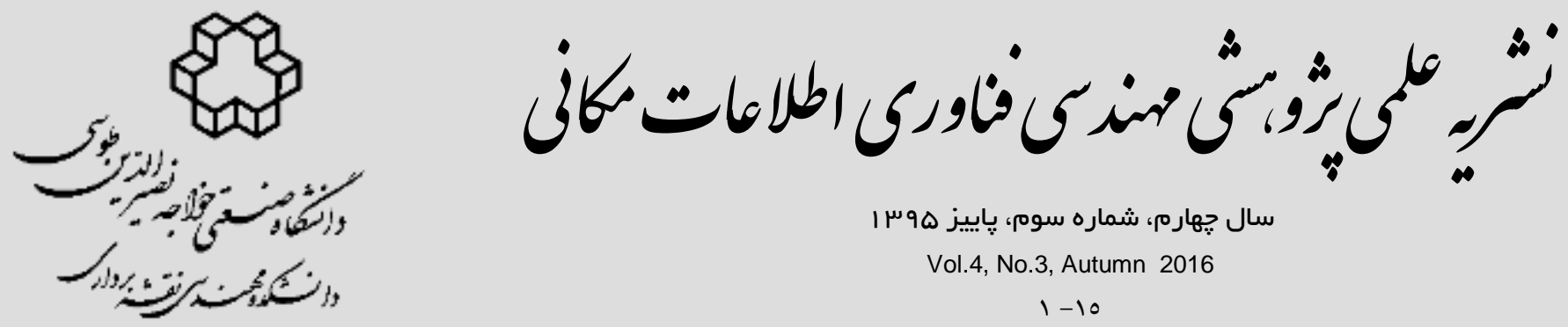

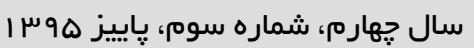
Vol.4, No.3, Autumn 2016

$1-10$

اين مقاله در اولين كنفرانس ملى مهندسى فناورى /طلاعات مكانى بهعنوان مقاله بركزيله انتخاب شده /ست كه بس /ز تكميل، داورى مجدد

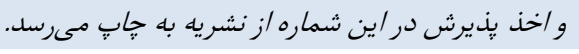

بررسى جڤشمانداز تغييرات سطح كشت اراضى كشاورزى در افق •r.r در حوضه زرينه رود با استفاده از روش تركيبى ماركوف - سلول هاى خودكار

غلامعباس سهولى'، مجيد دلاور "،.، محسن قمرى اصل"

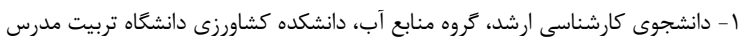

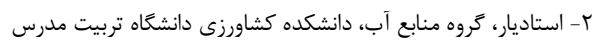

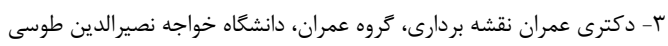

تاريخ دريافت مقاله:

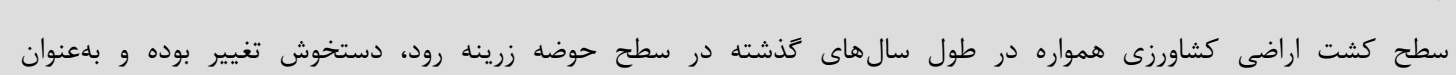

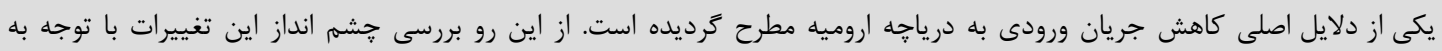

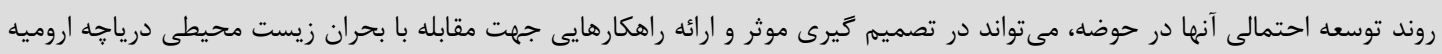

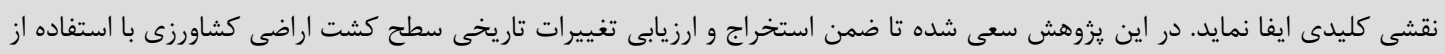

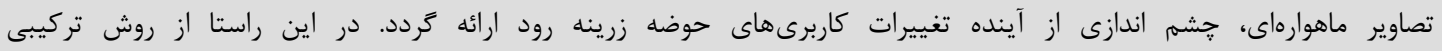

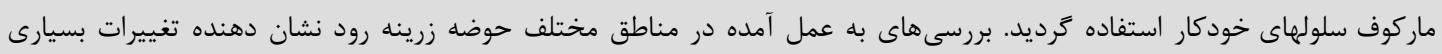

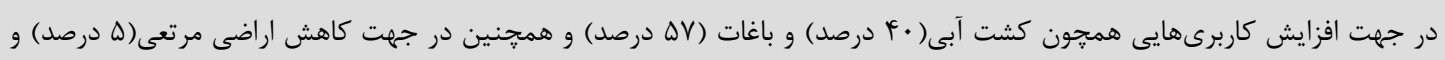

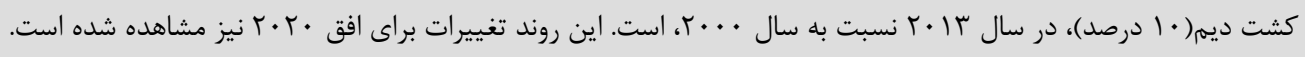




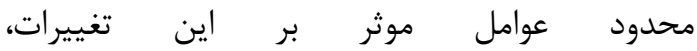

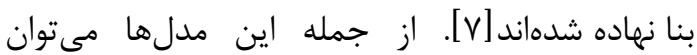

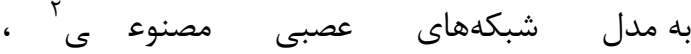

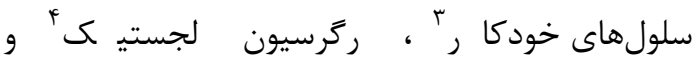

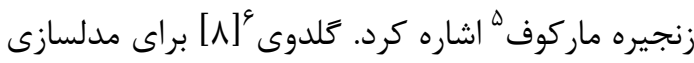
تغييرات كاربرى اراضى از روش ركرسيون لجستيك و

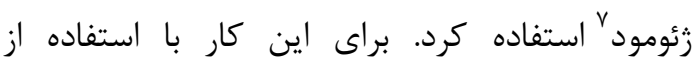

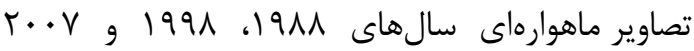

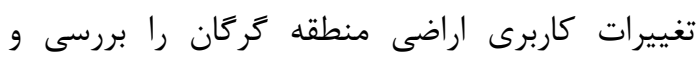

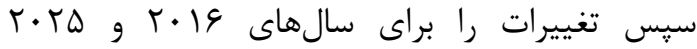
بيشبينى كرد. نتايج حاصل از اين كار شاهدى بر رأر رشد

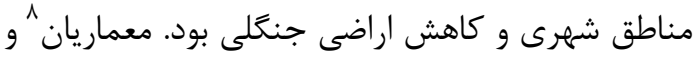

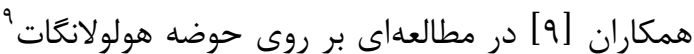

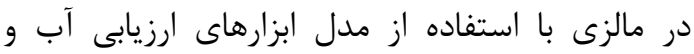

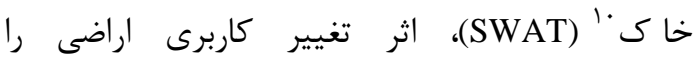

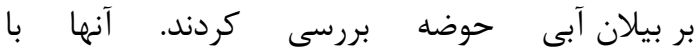

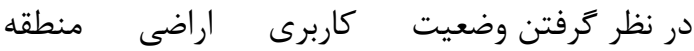

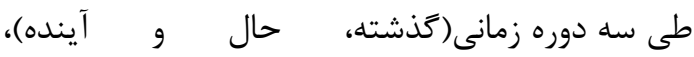
اثر تغييرات كاربرى را طى اين سالها بر رونه روى خروجى حوضه بررسى كرده و دريافتند كه شبيه سازى

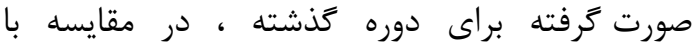

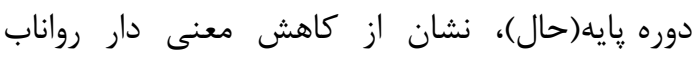
مستقيم ماهانه حوضه دارد. اين در حاليست كه يس إن از شبيهسازى تغييرات كاربرى در آينده (با استفاده از آنا

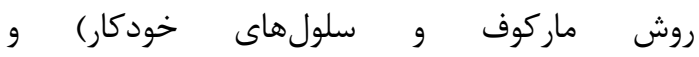
اجراى مجدد مدل، اثر اين تغييرات (در مقايسه با دروه پايه) در جهت افزايش معنىدار رواناب مستقيم آنمات ماهانه حوضه بوده است. يس از مقايسه تغييرات حاصله

\footnotetext{
${ }^{2}$ Artificial Neural Networks

${ }^{3}$ Cellular automata

${ }^{4}$ logistic regression

${ }^{5}$ Markov chain

${ }^{6}$ Goldavi

${ }^{7}$ GEOMOD

${ }^{8}$ Memarian

${ }^{9}$ Hulu Langat

${ }^{10}$ Soil and Water Assesment Tools
}

همواره در اكوسيستمهاى طبيعى، بهرهبردارى از زمين و

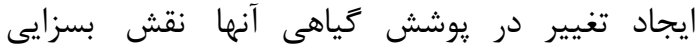

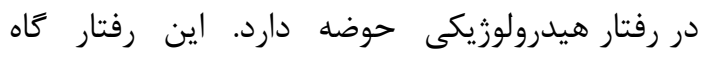
به صورت تغييراتى در رواناب خروجى از حوضه آبريز

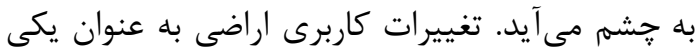

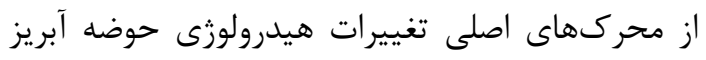

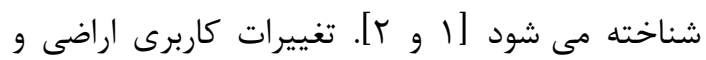

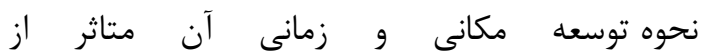

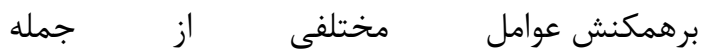

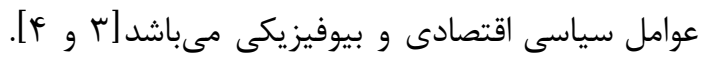
برآوردى از جشم انداز آينده تغييرات كاربرى اراضى بئى

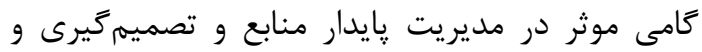

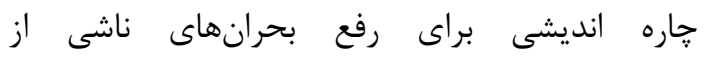
توسعه بىرويه كاربرىها خواهد بود. رويكرد آناليز سناريوها براى تغيير در كاربرى اراضى منطقه متناسب با روند توسعه منطقه، از جمله روشهاى معمول

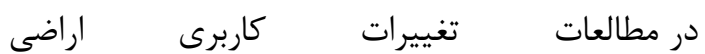
محسوب مى گردد[مو 8]. رويكرد سناريوهاى فرضى به محققين اجازه مى دهد كه به ارزيابى كلى روند تغييرات

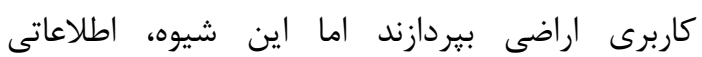

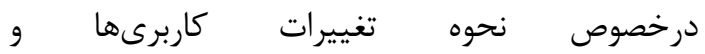
يراكنش احتمالى آنها در آينده در اختيار قرار نمىدهدي.

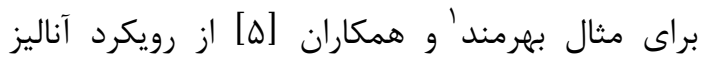

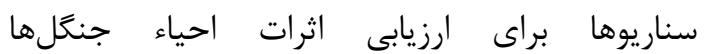
بر روى هيدرولوزى حوضه استفاده كردهاند.

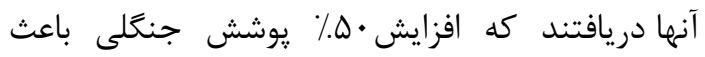

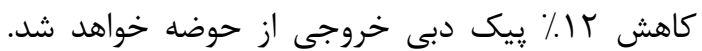

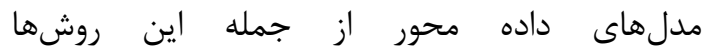

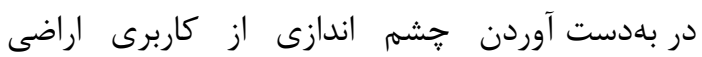

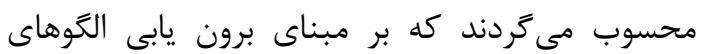
تغييرى كه در كذشته نزديك مشاهده شدهاند، با ارائه

${ }^{1}$ Bahremand 
مياندوآب، صائيندز، تكاب و سقز از كانونهاى مهمم شهرى اين حوضه هستند [1] در اين مطالعه جهت استخراج نقشه كاربرى اراضى

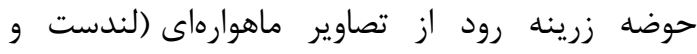

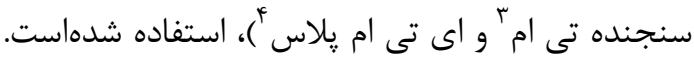

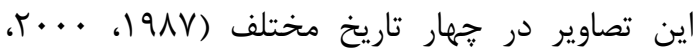

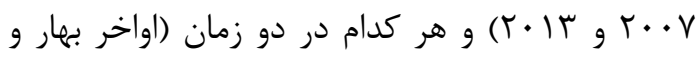

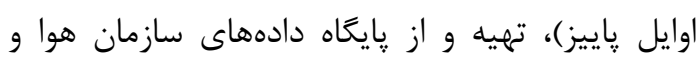

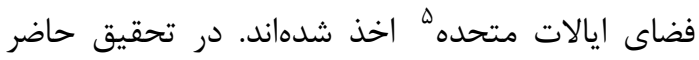

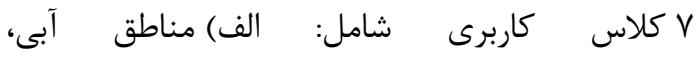

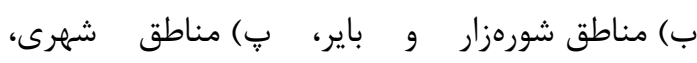

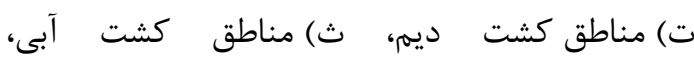
ج) مناطق باغى و ج) مناطق مرتعى در نظر كرفته شد.

\section{CA-r-r روش مار كوف- ســلولهـاى خودكــار}

(Markov

روش تركيبى ماركوف- سلولهاى خودكار از جمله

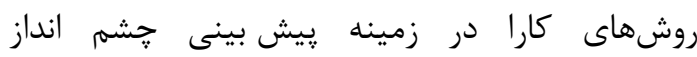

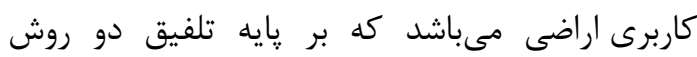
ماركوف و سلولهاى خودكار بنا نهاده شده است.

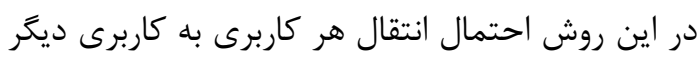

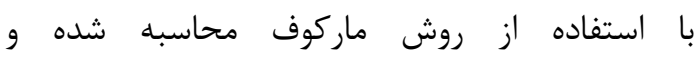

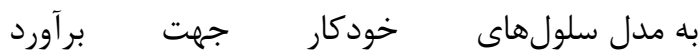

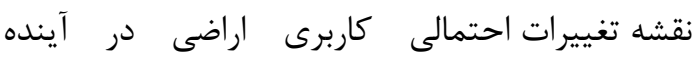

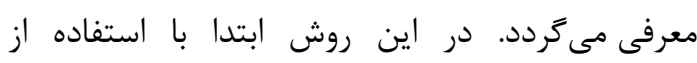

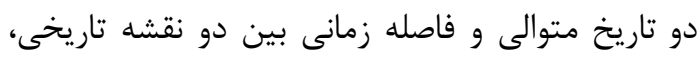

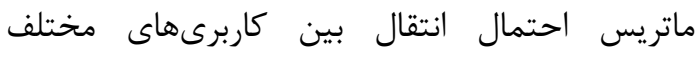

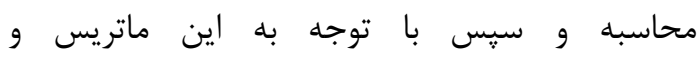

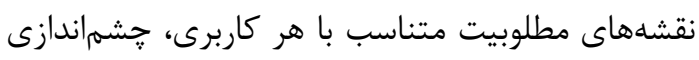

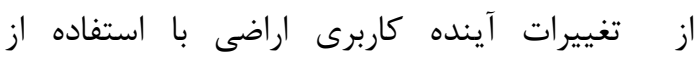

${ }^{3} \mathrm{TM}$

${ }^{4}$ ETM+

${ }^{5}$ http://earthexplorer.usgs.gov
در افق آينده كاربرىها در اين إين منطقه،

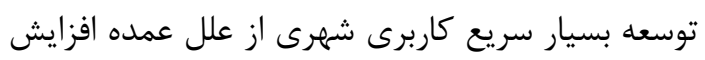

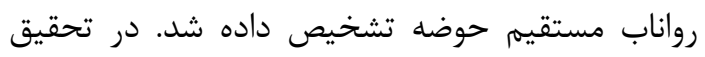

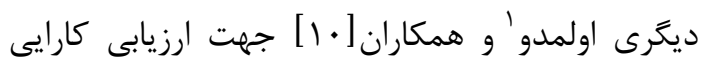

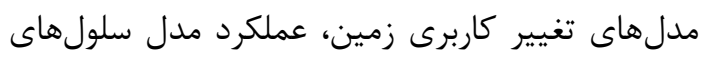

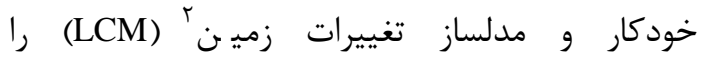

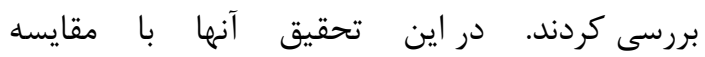

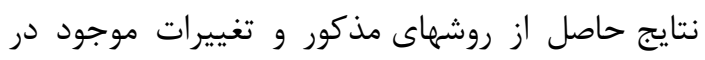

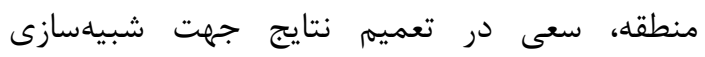
تغييرات براى آينده را داشتند. آنها براى اطمينان از

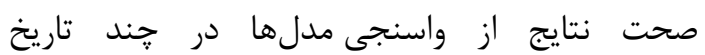

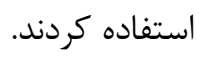

با توجه به آنجه آمد تحقيق حاضر در يى بررسى

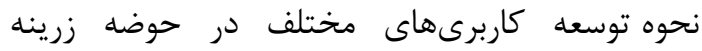

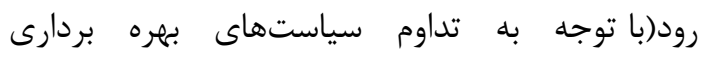
موجود در منطقه) و در نهايت ارائه جشماندازى از تراز

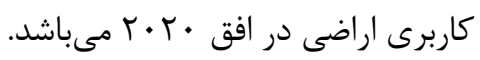

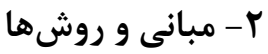

در اين بخش به تشريح منطقه مطالعاتى و همجنين

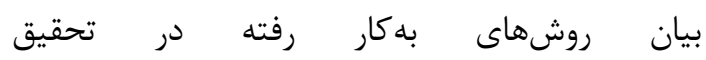

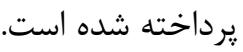

r-1- منطقه مطالعاتى

زيرحوضه آبريز زرينهرود، بزركترين زيرحوضه درجه

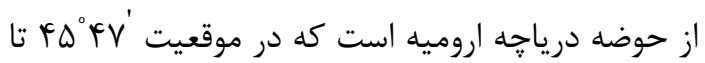

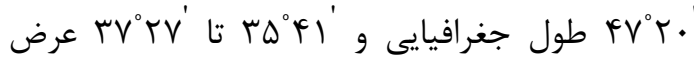

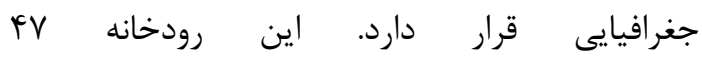

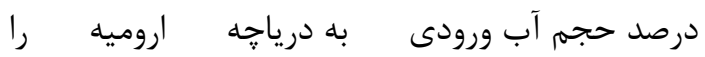

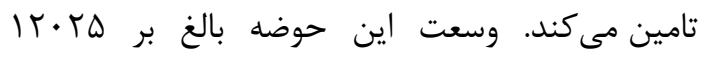

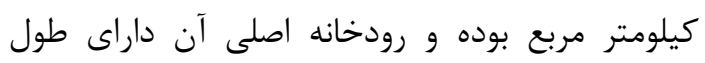

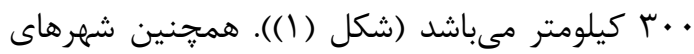

\footnotetext{
${ }^{1}$ Olmedo

${ }^{2}$ Land Change Modeler
} 
روش سلولهاى خودكار بهدست خواهد آمد. در ادامه به جزئيات مربوط به هر مرحله اشاره مى كردد.

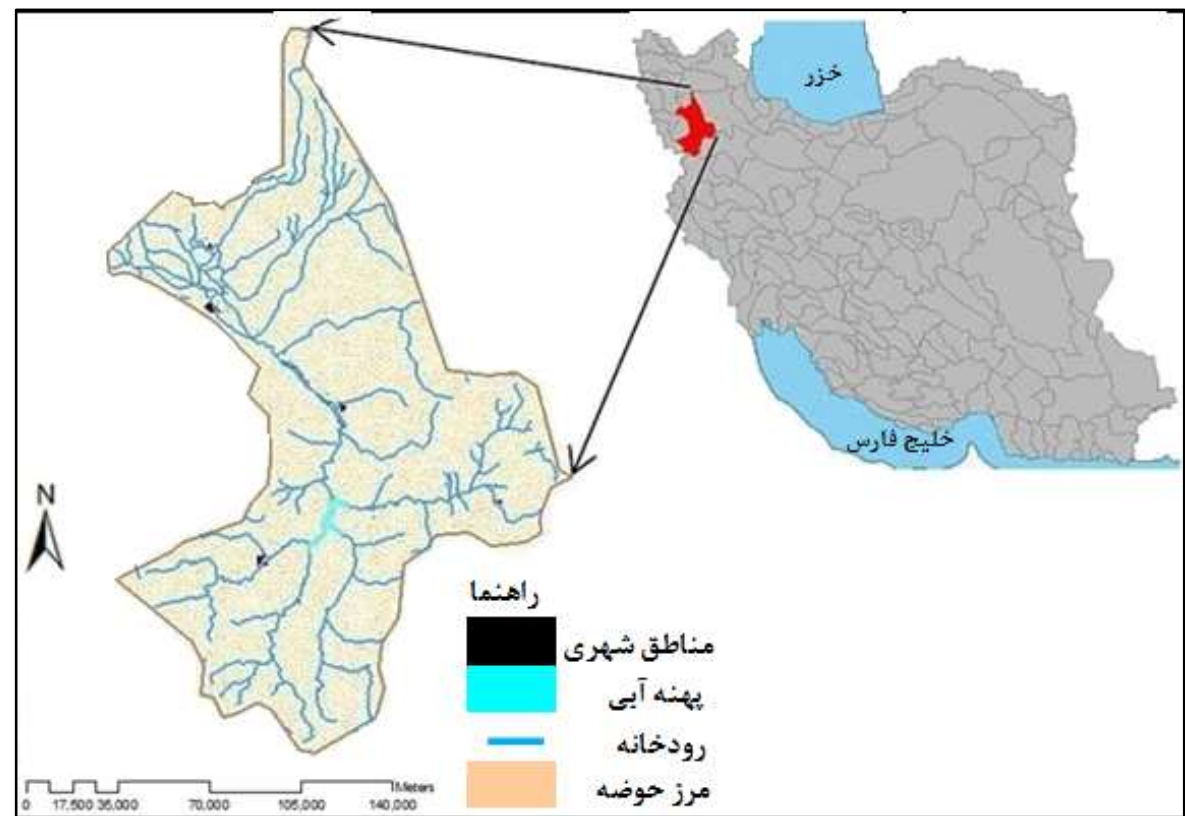

شكل 1: منطقه مورد مطالعه

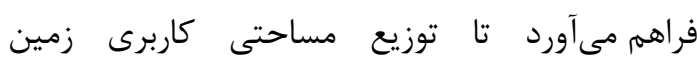

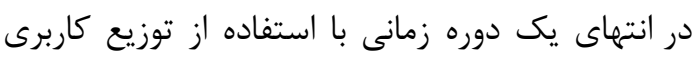
در ابتداى دوره و همجنين يك ماتريس تغيير وضعيت كه نشان دهنده تغييرات كاربرىها در طول دوره زمانى دورئ

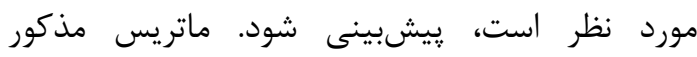

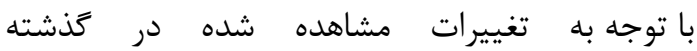
بلهدست آمده و براى ييشبينى تغييرات در آينده

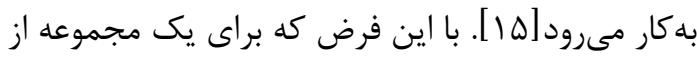
حالات كسسته (انواع كاربرىها)، وجود دارد. اين فرآيند در يك زمان معين تنها مىتواند

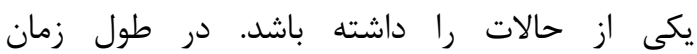

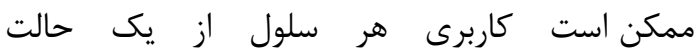

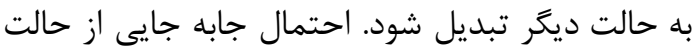

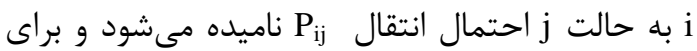

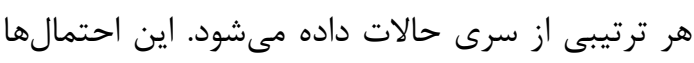

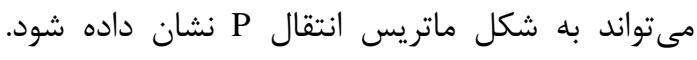

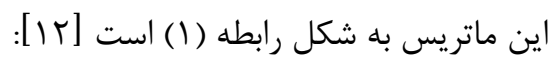
$P=\left[\begin{array}{ccc}\text { P11 } & \cdots & \text { P1n } \\ \vdots & \ddots & \vdots \\ \text { Pn1 } & \cdots & \text { Pnn }\end{array}\right] \quad$ (1)

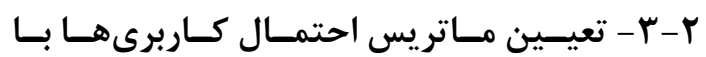
استفاده از روش ماركوف

مدلسازى ماركوف(زنجيره ماركوف) اساساً

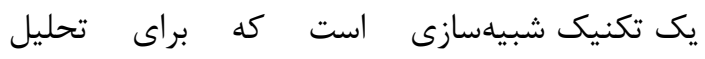

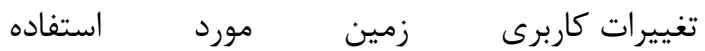

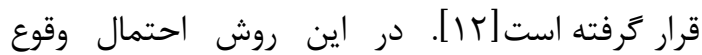

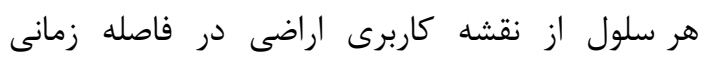
دادهشه به صورت زنجيره ماركوف و به زمان كذشته

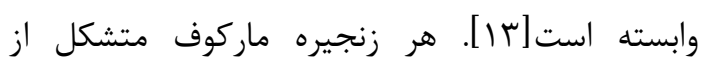

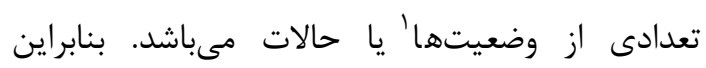

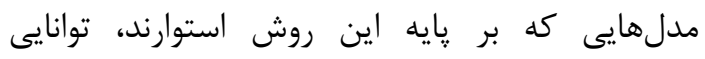

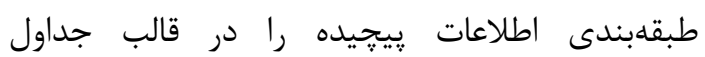
تغيير وضعيت، دارند. با استفاده از اين روش مئتوان

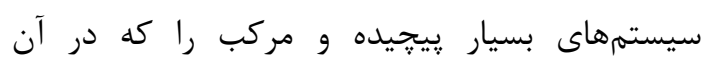

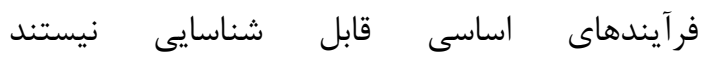

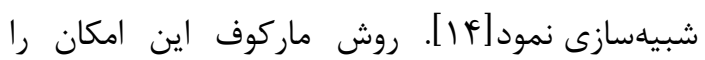

${ }^{1}$ Transition probabilities 
يافتن نقطه تحول احتمالى در سرى دادهها،

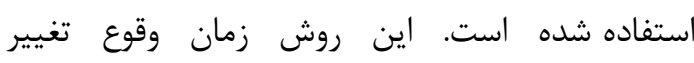

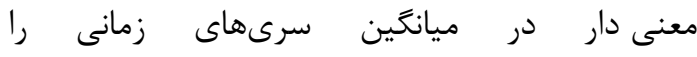

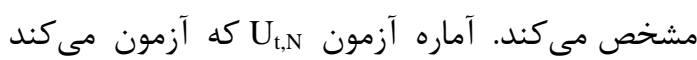
كه آيا دو مجموعه نمونه

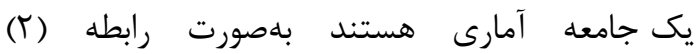

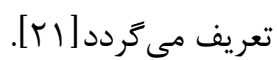

$U_{t, N}=U_{t-1, N}+\sum_{j=1}^{N} \operatorname{sgn}\left(X_{t}-X_{j}\right)$

(T) (T) $\mathrm{t}=2, \ldots, \mathrm{N}$

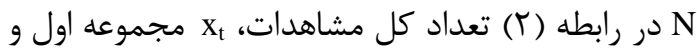

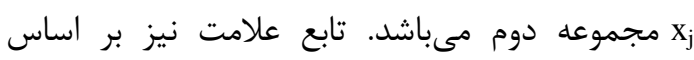

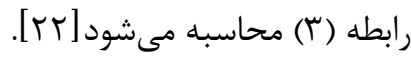

$\operatorname{sgn}(x)=\left\{\begin{array}{ccc}+1 & \text { if } & x>0 \\ 0 & \text { if } & x=0 \\ -1 & \text { if } & x<0\end{array}\right.$

(广) رابطه (r)

آماره آزمون و احتمال وقوع مرتبط با آن توسط روابط (f و هار) محاسبه خواهند شد.

$K_{N}=\max _{1 \leq t \leq N}\left|U_{t, N}\right|$

(ابطه (F)

$P \cong 2 \exp \left\{-6\left(K_{N}\right)^{2} /\left(N^{3}+N^{2}\right)\right\}$

(a) (aط)

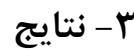
در اين بخش نتايج ارائه خواهد شد.

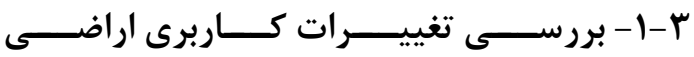
در دوره تاريخى

نقشه كاربرى اراضى بـــاى حوضـهـ مـورد بــا اسـتفاده از

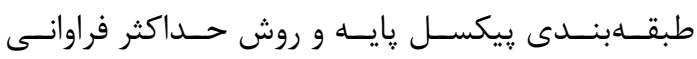

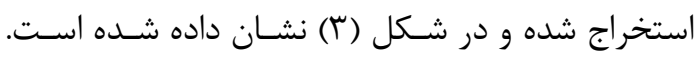

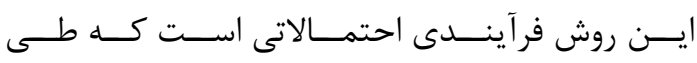

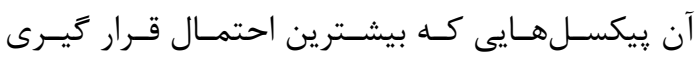

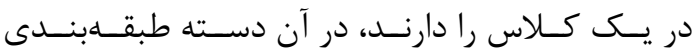

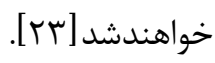

از آنجا كه عناصر ماتريس غير منفى هستند و

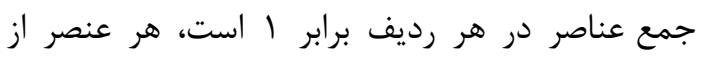

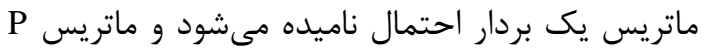
يك ماتريس احتمال است[19].

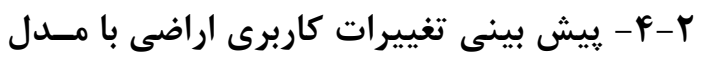
سلول هاى خودكار مدل سلولهاى خودكار يك تكنيك مدلسازى است

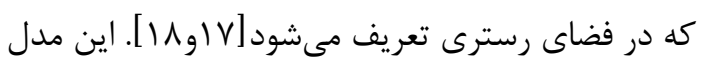
از يويايى و كستتگى برخوردار است كه در مدلسازى رخدادهاى طبيعى و انسانى بهكار مىرود. فضايى كه

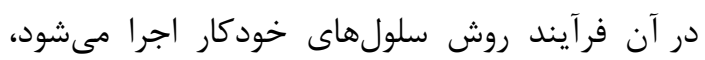

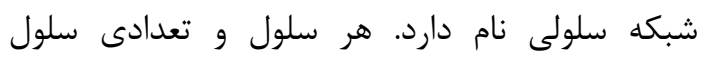

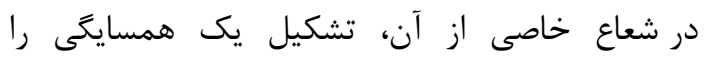

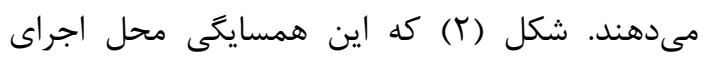

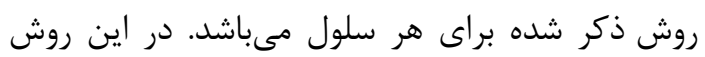

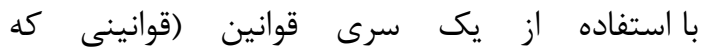

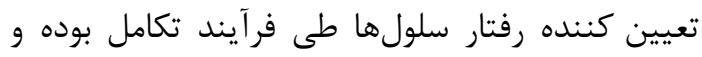

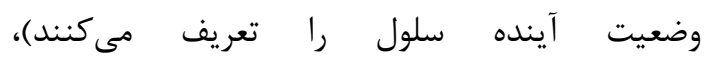
حالات سلولها در طول زمان تغيير مى كند. در مدل

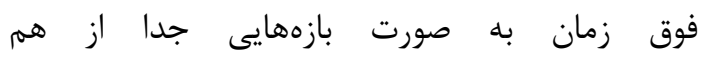
تعريف شده است و تعداد اين بازههاى زمانى بانى بسته به هدف مدلسازى، متفاوت مىباشد [ [1 ]ـ.

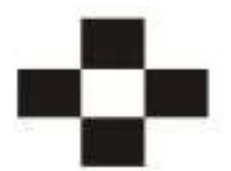

$$
\text { شكل ז: همسايكى ז×r در مدل دو بعدى }
$$

r-ه- نقطه تحول با استفاده از آزمون يتيت'

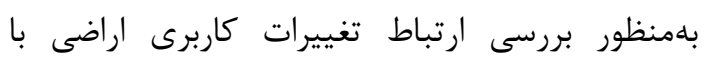

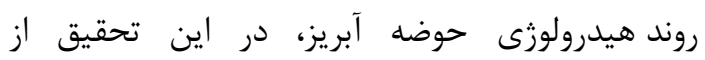

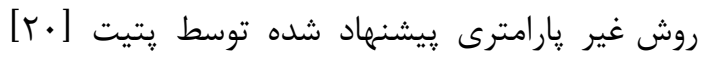

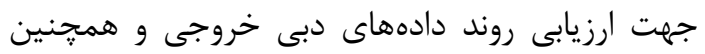

\section{${ }^{1}$ Pettett}




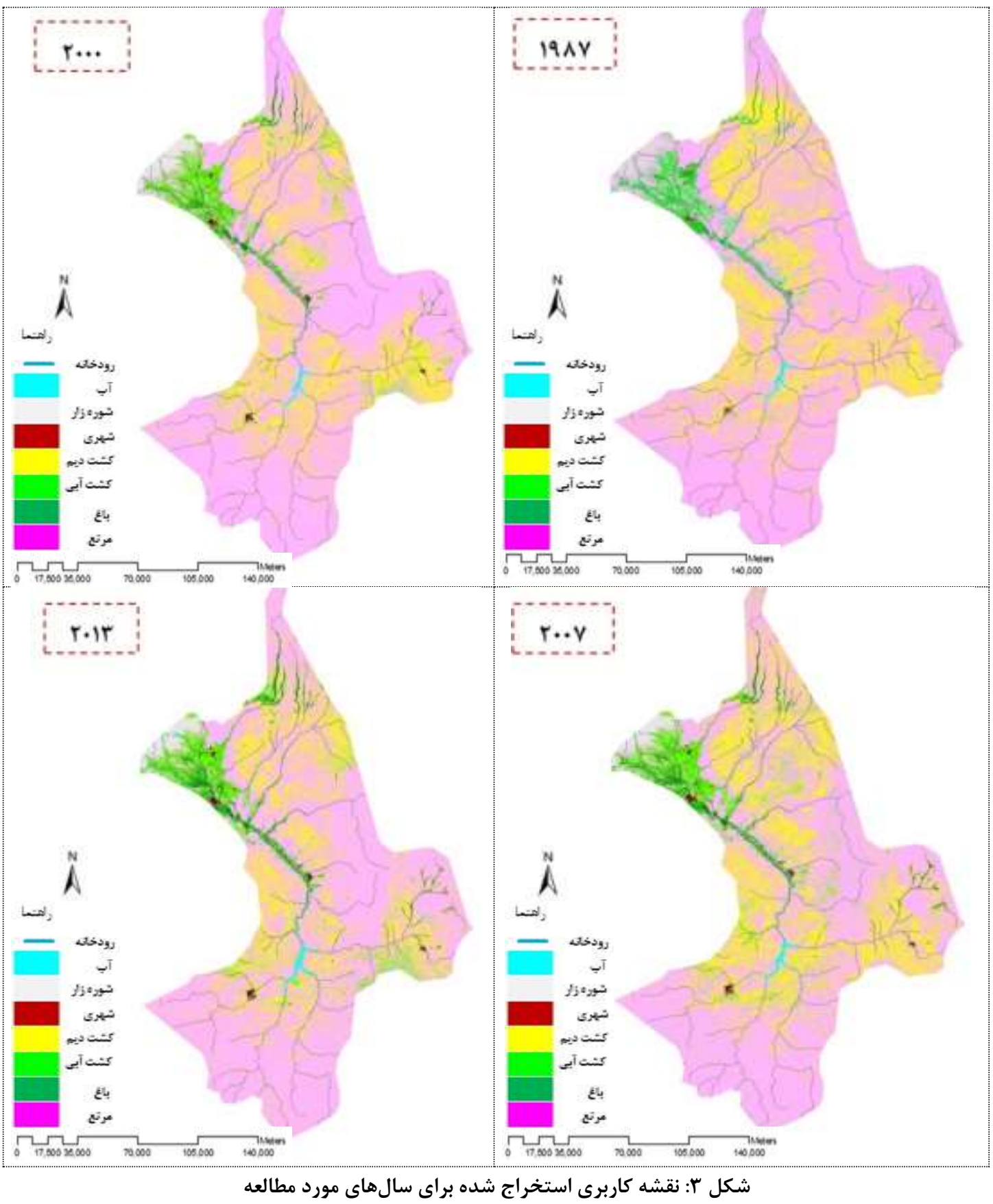

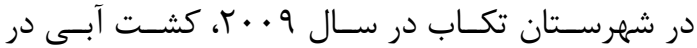
يايين دست سد به سبب فراهم شدن آب كافى، افزايش يافته است. جهت مقايسه هم زمان تغييرات هر كدام از

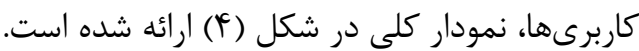
طبـق شـكل(Y) و جــدول (1)، جهــت كلـى تغييـرات

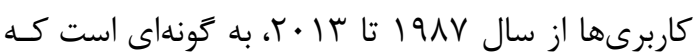

همانطور كه در نقشه كاربرى در سالهاى مورد مطالعـه

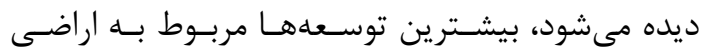

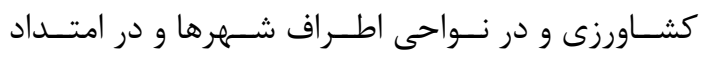

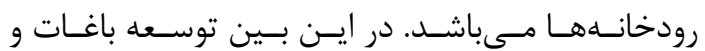

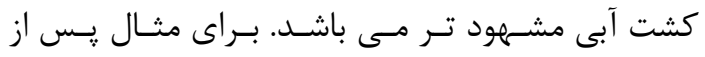

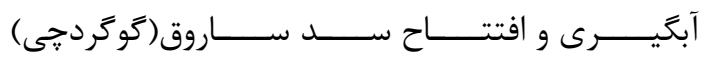


حوضه حاكى از آن اسـت كـهـ تغييـرات بـارش در ايـنـ

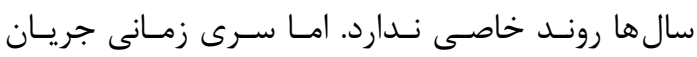

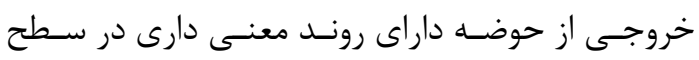

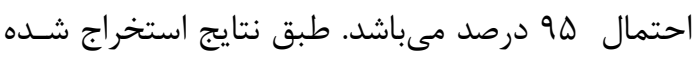

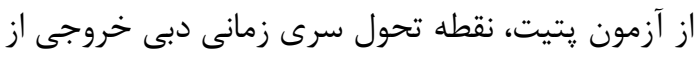

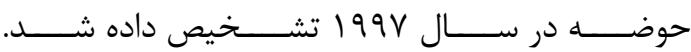

منجر به افزايش كـاربرى شهرىى، آبسى، شـورهزار، بـاغ،

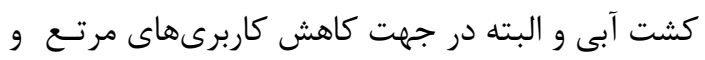
كشت ديم است. به منظور بررسى ارتباط اين تغييـرات

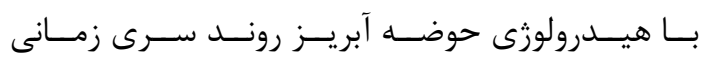

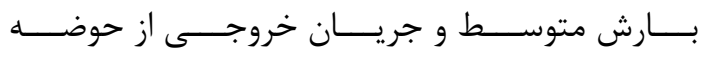

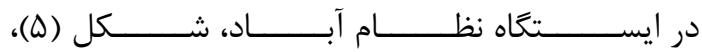

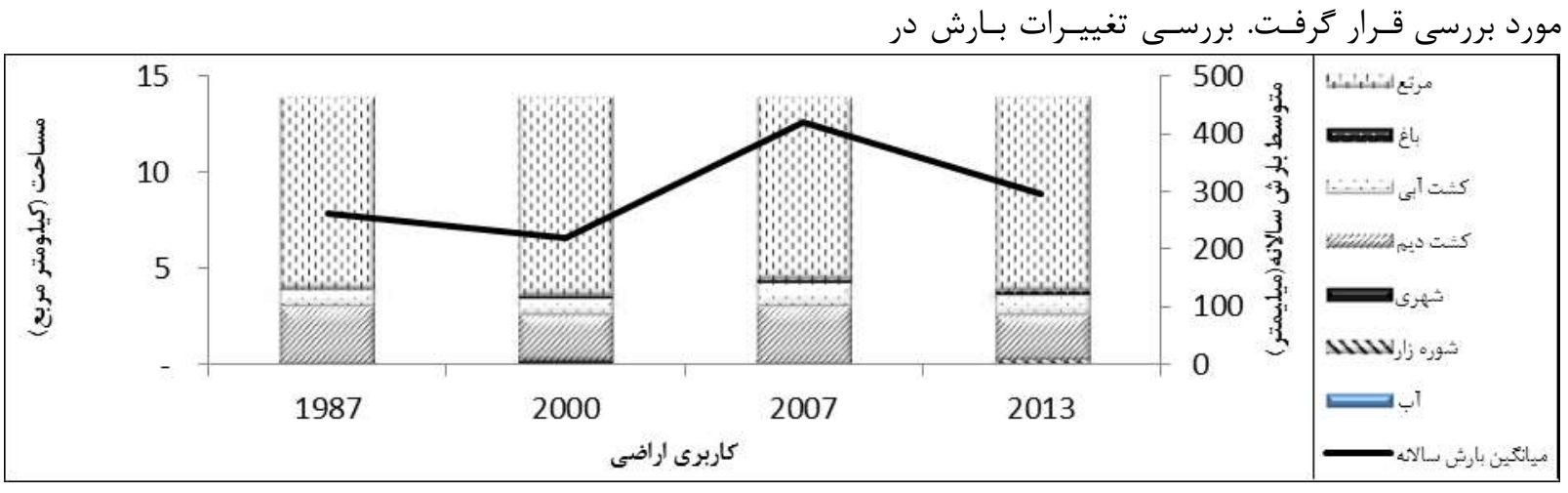

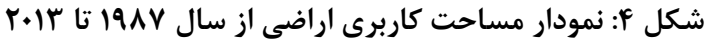

جدول ا: مساحت كاربرىهاى مختلف در سال هاى مورد مطالعه

\begin{tabular}{|c|c|c|c|c|c|c|c|c|}
\hline \multirow{2}{*}{ كاربرى } & \multicolumn{2}{|c|}{$191 \mathrm{~V}$} & \multicolumn{2}{|c|}{$r \ldots$} & \multicolumn{2}{|c|}{$r . . V$} & \multicolumn{2}{|c|}{$r+1 r$} \\
\hline & $\mathrm{KM}^{2}$ & $\%$ & $\mathrm{KM}^{2}$ & $\%$ & $\mathrm{KM}^{2}$ & $\%$ & $\mathrm{KM}^{2}$ & $\%$ \\
\hline آب & rG.V & זr/. & r... &.$/ 49$ & fr.q & . & 94.9 &.$/ 4 G$ \\
\hline شوره زار & $|f| . \Delta$ & $1 / \cdot 1$ & $r \cdot 9 . r$ & $1 / 4 q$ & IQF.V & $1 / 1$. & 19V.r & $|/ 4|$ \\
\hline شهرى & rT.D & 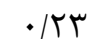 & fF. & | & fa. & 低 & 41.r & $\cdot \mid q F$ \\
\hline كشت ديم & r人৭9.F & $r \cdot 199$ & rrAD.D & $\mid V / \cdot T$ & TAFT.D & $r \cdot / r q$ & TMT.D & $19 / \Delta \varphi$ \\
\hline كشت آبى & 119.9 & $\Delta / \wedge \Delta$ & NTr. & $\Delta / 9 F$ & $1 r \cdot 9.1$ & N/G & $1 \cdot \mu F \cdot F$ & $V / \mu \Lambda$ \\
\hline باغ & 119.0 & $\cdot 1 \wedge \Delta$ & 194.0 & $1 / 1 \mathrm{~V}$ & rब9.r & $1 / \wedge \Delta$ & $r \vee \wedge .9$ & $1 / 99$ \\
\hline مرتع & $q ৭ \Delta F^{\prime} . q$ & $V M / \cdot r$ & 1. MFT.G & $V \Psi / \Lambda$. & $94 \Delta 9$. & $q V / 4 q$ & $1 \cdot \Delta V . q$ & $V I / V V$ \\
\hline
\end{tabular}

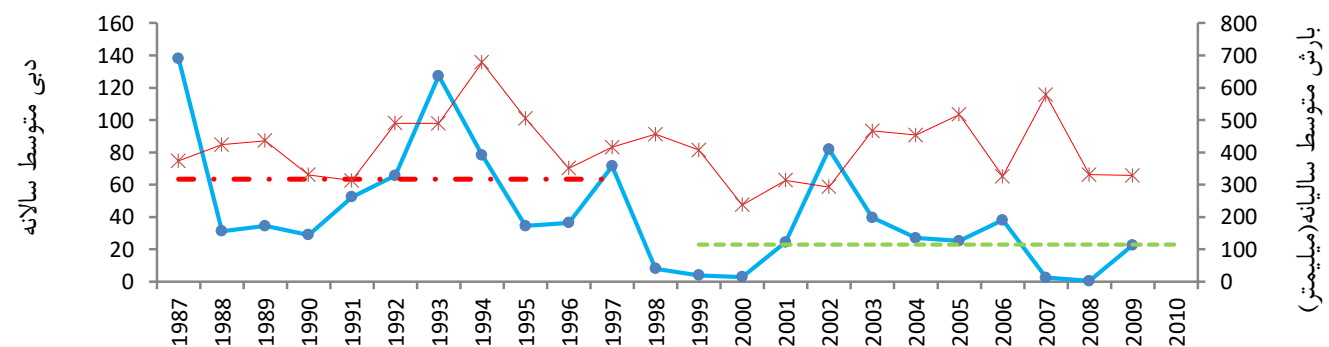

طول دوره آمارى

\begin{tabular}{|c|c|c|c|}
\hline 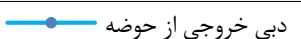 & $-\cdots$ mu1=63.477 & $-----m$ mu2 $=22.986$ & بارش بر روى حوضه ــــــ \\
\hline
\end{tabular}




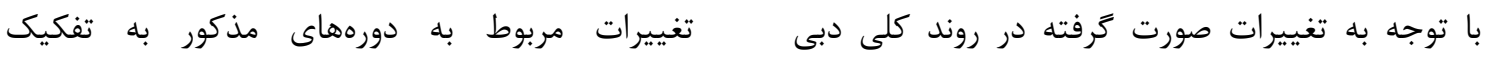
خروجى ل باز

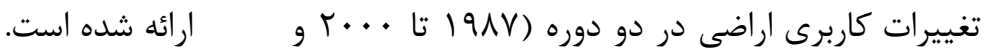

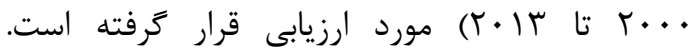

جدول ז: درصد تغييرات كاربرىهاى مختلف در استانهاى منطقه مورد مطالعه

\begin{tabular}{|c|c|c|c|c|c|c|c|c|}
\hline \multicolumn{9}{|c|}{ آذربايجان شرقى } \\
\hline \multicolumn{2}{|c|}{ كاربرى اراضى } & آب & شوره زار & شهرى & كشت ديم & كشت آبى & باغ & مرتع \\
\hline \multirow{2}{*}{1} & $\mathrm{KM}^{2}$ & T.VF & $1 \cdots . t$ & $1 . V$ & reV.9 & $\Lambda \wedge .1$ & 51.9 & $|\Delta \wedge .|^{f}$ \\
\hline & $\%$ & $-198 / 9$ & $\Delta F / \varphi$ & $\Delta / 9$ & $-r \Delta / \varphi$ & $I T / \Lambda$ & $11 / 9$ & $F / T$ \\
\hline \multirow{2}{*}{$r$} & $\mathrm{KM}^{2}$ & $V .9$ & $11 . V$ & 11.9 & 190.9 & rr.s & $1 \cdot f . r$ & - \\
\hline & $\%$ & $r \Delta \xi / r$ & $-F / 1$ & $\mathrm{Fr/V}$ & $1 N / r$ & $\mu /$ & $V \Delta$ & $-\Lambda / 9$ \\
\hline \multicolumn{9}{|c|}{ آذربايجان غربى } \\
\hline \multicolumn{2}{|c|}{ كاربرى اراضى } & آب & شوره زار & شهرى & كشت ديم & كشت آبى & باغ & مرتع \\
\hline \multirow{2}{*}{1} & $\mathrm{KM}^{2}$ & - & V.IV & I. & $-f q 4 . \Delta q$ & $r .90$ & \&\&.ఎV & qrq.V \\
\hline & $\%$ & $-r \cdot / 1$ & $19 / 4$ & $91 / 9$ & $-r I / D$ & $\cdot 11$ & $99 / 0$ & $\mathrm{~V} / \mathrm{\Lambda}$ \\
\hline \multirow{2}{*}{$r$} & $\mathrm{KM}^{2}$ & T9.99 & -9.19 & $\Lambda . r \Delta$ & & INY.TY & VI. Af & - FF.D \\
\hline & $\%$ & $\Lambda \mathrm{V}$ & $-1 / / \Lambda$ & rᄉ/r & $-1 \pi / 4$ & rV & $9 \pi / T$ & $-\cdot / V$ \\
\hline \multicolumn{9}{|c|}{ كردستان } \\
\hline \multicolumn{2}{|c|}{ كاربرى اراضى } & آب & شوره زار & شهرى & كشت ديم & كشت آبى & باغ & مرتع \\
\hline \multirow{2}{*}{1} & $\mathrm{KM}^{2}$ & $-\cdot$ Ff $^{\mathrm{F}}$ & $-1 . \cdot 1$ & 9.41 & $r \cdot . V V$ & $-\Delta 9 . \Delta \Lambda$ & $-1 . \cdot 1$ & IT.IT \\
\hline & $\%$ & $-1 / 1$ & $-9 T / K$ & $91 / 0$ & $F / \Lambda$ & $-\Delta \varphi$ & IT/ & $\cdot / T$ \\
\hline \multirow{2}{*}{$r$} & $\mathrm{KM}^{2}$ & $\wedge . \wedge V$ & $-\cdot \Delta V$ & $0 . r q$ & $-\wedge \wedge .9 \vee$ & 111.9 & $-r . r \Delta$ & $-M F$. \\
\hline & $\%$ & re/V & -95 & rr & -1 & $r \Delta \cdot / \Lambda$ & $-G Y / T$ & -.19 \\
\hline \multicolumn{9}{|c|}{ زنجان } \\
\hline \multicolumn{2}{|c|}{ كاربرى اراضى } & آب & شوره زار & شهرى & كشت ديم & كشت آبى & باغ & مرتع \\
\hline \multirow{2}{*}{1} & $\mathrm{KM}^{2}$ & $\because \cdots \wedge$ & . & $\cdot . M F$ & tr.t人 & $-10 . V \cdot$ & $r .90$ & 9.11 \\
\hline & $\%$ & $9 \ldots$ & . & $1 \cdot \Delta / \Lambda$ & $1 \cdot 19$ & $-11 / 1$ & $r q \Delta / \Delta$ & $1 / 9$ \\
\hline \multirow{2}{*}{$r$} & $\mathrm{KM}^{2}$ & $-\cdot .99$ & $\cdot .114$ & $-\cdot \cdot \cdot V$ & r..人 & $|| f \mid$. & V.19 & - - \\
\hline & $\%$ & -1. & $1 / \pi$ & $-r G / V$ & $I T N / D$ & TN/G & $111 / 9$ & $-9 / 1$ \\
\hline
\end{tabular}

دوره مذكور مىباشد. همجنين در اين دوره شورهزار

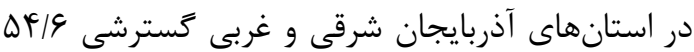

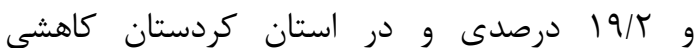
بالغ بر س/ أو درصد داشته است. باغات به دليل استفاده از منابع آب زير زمينى جهت آبيارى آنها همواره نسبت به بارندگى، ديرترين

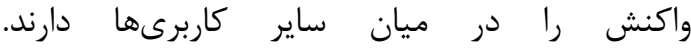

r-r- ارزيابى تغييرات كـاربرى اراضسى در دوره $19 \Lambda V-Y . .$. طبق جدول (r) در اين دوره مساحت كاربرىهاى آب و كشت ديم در همه استانها افت محسوسى داشته و

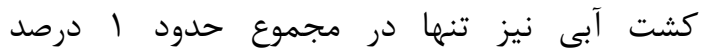
رشد دارد. از جمله دلايل اصلى كاهش محسوس كشت ديم در منطقه، كاهش نسبى بارش طى لى 


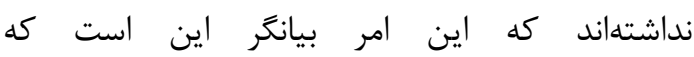
تغييرات كاربرىهاى بيشتر تبديل آنها به يكديكر بوده ائن و تبادل جندانى با مراتع نداشتهاند.

\section{r-F- ارزيابى روش ماركوف- سلولهاى خودكــار} در بيش بينى كاربرى اراضى

بلمنظور ارزيابى روش ماركوف- سلولهاى خودكار در بيش بينى كاربرى اراضى، نقشههاى كاربرى اراضى مارى

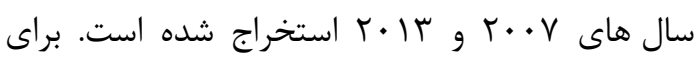
اين كار ابتدا با استفاده از نقشه كاربرى در دو تاريخ

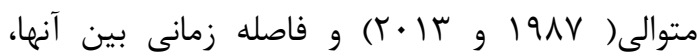

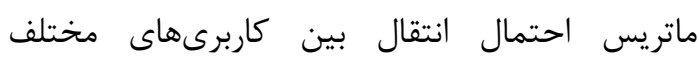
از طريق روش ماركوف محاسبه شده است. سيس آترائ نقشهاى مطلوبيت هر كاربرى از حيث توسعه آنها

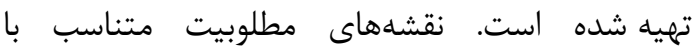
روند يیشروى هر كاربرى و با توجه به ضريب اهميت

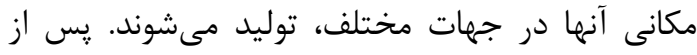

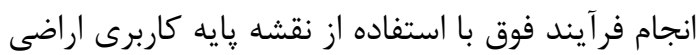

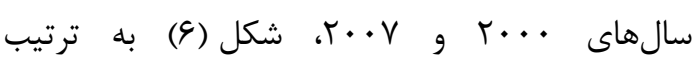

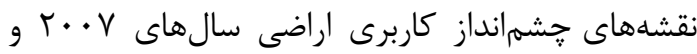
r ا • r استخراج و با نقشههاى مشاهداتى مقايسه كرديد. به منظور ارزيابى دقت بـيشبينـىهـاى انجـام شـده از ماتريس خطا و شاخصهاى دقـت كلى (ايسـن شـاخص

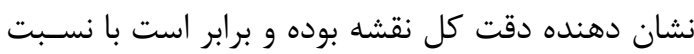

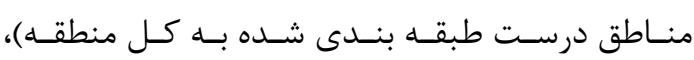

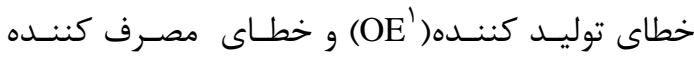

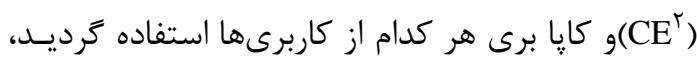

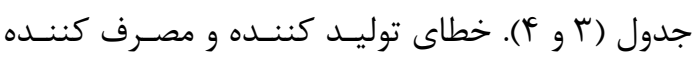

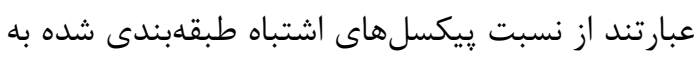
كل يِيكسلها و براى هر كاربرى قابل محاسبه مىباشد.

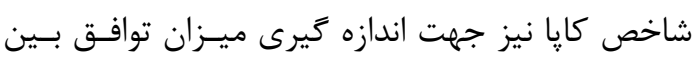

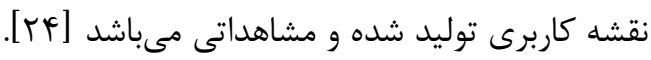

\footnotetext{
${ }^{1}$ Operator error

${ }^{2}$ Consumer error
}

در استانهاى آذربايجان شرقى و غربى و همجنين

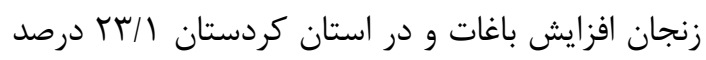

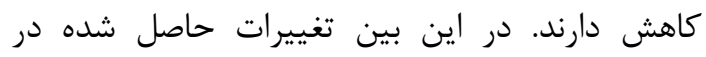

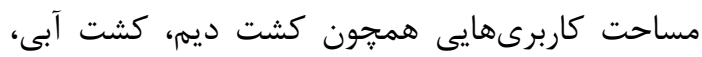

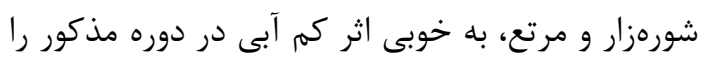

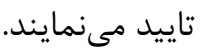

\section{ץ-ץ- ارزيابى تغييرات كـاربرى اراضسى در دوره $r+1 r-r+. \cdot$} در اين دوره ميزان بارشها قدرى افزايش يافته و دبى خروجى از حوضه نيز داراى روند يكنواخت دئرى

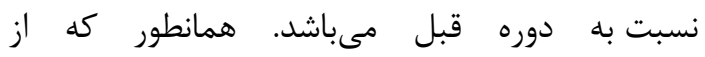
نقشه كاربرى موجود در شكل (Г) و همجنين نمودار

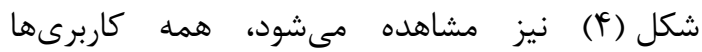

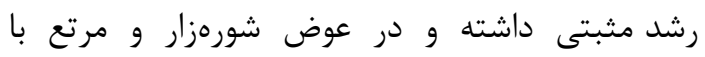
كاهش مساحت، نسبت به دوره قبل مواجه هستند. باتوجه به نمودار تغييرات كاربرى در دوره دوم، داحن

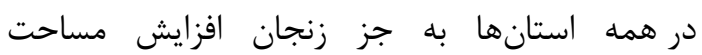

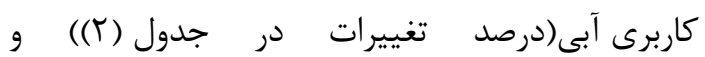
كاهش مناطق شورهزار به جشم مى خى خورد. كشت ديم

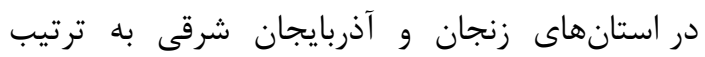

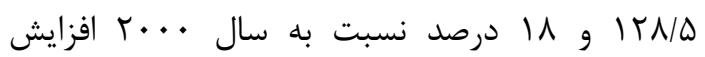

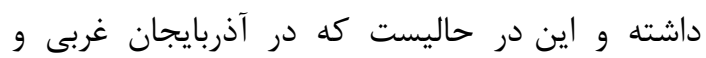

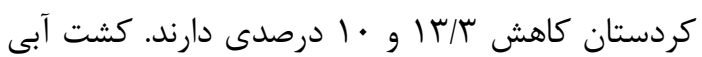

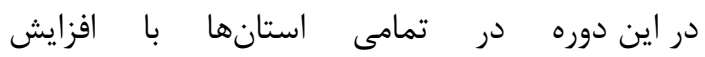

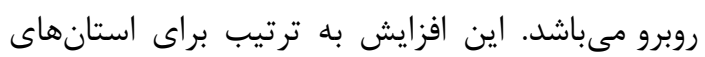

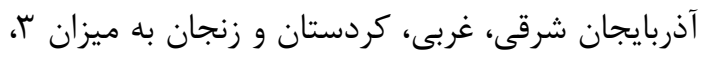

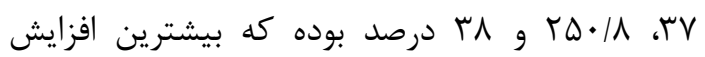

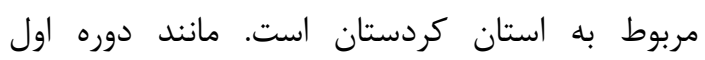
در اين دوره نيز باغات توسعه بيشترى داشتهاند

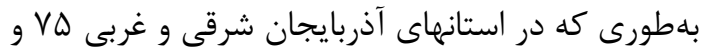

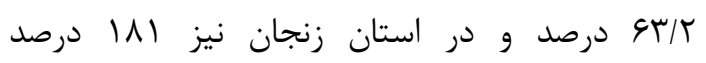
افزايش سطح داشتهاند اين نسبت براى استان كردستان

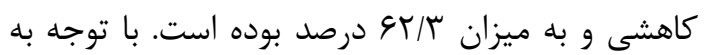

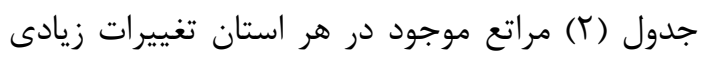



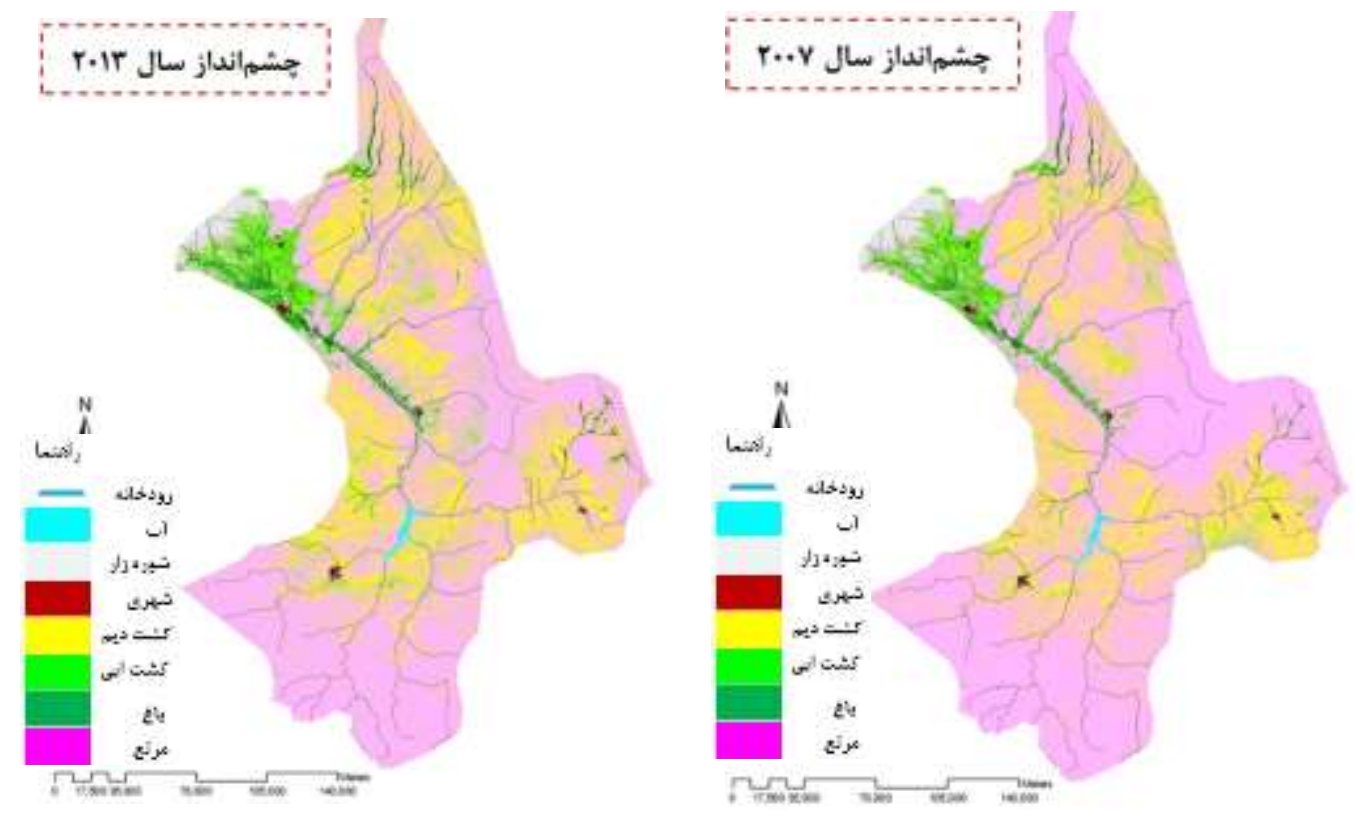

شكل 9: نقشههاى جشم انداز استخراج شده از طريق روش CA_MARKOV

جدول r: ماتريس خطا و شاخص كاياى كلى و جزئى سال V.+r

\begin{tabular}{|c|c|c|c|c|c|c|c|c|c|c|}
\hline > مشاهده & آب & شوره زار & شهرى & كشت ديم & كشت آبى & باغ & مرتع & جمع & $\mathbf{C E}$ & كايا \\
\hline آب & rir.v. & 1199 & Tr & fif & rovi & IIN & $\Delta G V F$ & rITINIFr & $\cdot 1 \cdot$ & .199 \\
\hline شوره زار & Ir人s & $|\Delta T| \cdot \Delta$ & $r \Delta V I$ & $I T \cdot V$ & $r \cdot 111$ & VIr & VDVAF & rOHANF & $\cdot / f$ & $\cdot 1199$ \\
\hline شهرى & rDI & 991 & r. r. & 1.人r & $q \wedge \Delta \wedge$ & 1998 & $\mid$ FTIN & $\Delta \wedge I V V$ & $\cdot / \mu V$ & $\cdot 19$ \\
\hline كشت ديم & 11. & ২91 & vVq & $\mid 491119$ & $1.9 V K F$ & $1 r \cdot 1$ & AVYTDI & 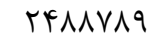 & $\cdot / 4 q$ & س \\
\hline كشت آبى & TYTY & DTYF & VDIV & $1 \cdot \Delta \Delta Y$. & $F V \cdot q k$. & IrGDVF & TMTATI & $9 G . r T \wedge$ & $\cdot 10$ & سז/. \\
\hline باغ & س & rd & $1 \wedge F$ & 1.970 & $|r V \cdot r|$ & IIVEVD & r. १६. & TVAIET & $\cdot / \Delta V$ & $\cdot / T^{q}$ \\
\hline مرتع & GTIT & $৭ \hookrightarrow \Delta \wedge$ & $\Lambda \Delta V r$ & IOHVTGF & 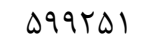 & rN19r & $q Y \Delta \cdot q \wedge F$ & IIFF. THF & .119 & • \\
\hline جمع & rIMAK & lsvq4. & 19949 & rIDQHFq & r.r & rAVITr & 1. FVVEqR & rGVqVVTV & & \\
\hline $\mathrm{OE}$ & - & $\cdot 11$ & $\cdot / K^{c}$ & $\cdot \mid \Delta T$ & $\cdot 190$ & .109 & .115 & & $\cdot / 1$ & \\
\hline كايا & .199 & .19 & $\cdot \mid \Delta T$ & $\cdot \mid \Delta \varphi$ & $\cdot / 4 V$ & $\cdot|f|$ & $\cdot / V r$ & & & $\cdot|\lambda|$ \\
\hline
\end{tabular}


بررســى جِشــم انــداز تغييـرات ســـح كشــت اراضـى...

غلامعباس سهولى، مجيد دلاور"، محسن قمرى اصل

جدول F: ماتريس خطا و شاخص كاياى كلى و جزئى سال rا+r

\begin{tabular}{|c|c|c|c|c|c|c|c|c|c|c|}
\hline "جشم اندانيخ & آب & شوره زار & شهرى & كشت ديم & كشت آبى & باغ & مرتع & جمع & $\mathbf{C E}$ & كايا \\
\hline آب & TITIV•DI & ITT. & 11 & $r 90$ & rDQT & ITF. & $r \cdot \Delta \lambda$ & TITTEFTA & • & .199 \\
\hline شوره زار & TEAT & lg4qVA & IDVA & $V F$ & $\Lambda F \wedge I$ & rd & $|9| \cdot 0$ & سזوسوו & $\cdot / 14$ & $\cdot \mid \Lambda F$ \\
\hline شهرى & $r \cdot l$ & lG94 & rqTFD & 990 & qrr. & $|\Delta|$. & س & DQTIN & س & .199 \\
\hline كشت ديم & $9 \cdot 9$ & M & $1 \cdot V V$ & IDTDGIT & IgrVDA & 1.991 & IrquqVA & 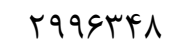 &.$/ 4 q$ & $\cdot / 4 V$ \\
\hline كشت آبى & $\Delta 9 ६ \wedge$ & I91TK & $119 \cdot 1$ & 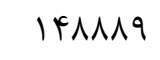 & $\Delta \vee \backslash \Delta \varphi$. & $1 \cdot \Delta V F^{\prime} 1$ & DIFrqf & IrVATVD & $\cdot 101$ & $\cdot / \pi q$ \\
\hline باغ & ऍ人9т & 111 & $\varphi \Delta V$ & $q \cdot 11$ & $19 \cdot 114$ & INTFTD & $r \Delta \Delta V V$ & r人rqץ. & . IDT & $\cdot / F V$ \\
\hline مرتع & $1.44 \Delta$ & 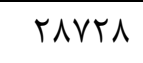 & $\mid$ & 1q.rrq & rrqIQ1 & 919. & 9 TA19.r & $1 \cdot 4 \varepsilon \cdot \Delta \wedge \Delta$ & .111 & . \\
\hline جمع & rIrFI. fG & TIGAFA & GNIT. & $r \Delta V Y q \Delta r$ & llfFart & $r . q 1 \vee q$ & WIFTEFq & TEVqVVTV & & \\
\hline $\mathrm{OE}$ & · & $\cdot / T F$ & . let & $\cdot / f$ & $\cdot 10$ & $\cdot / f$ & $.11 \mathrm{~V}$ & & .11 & \\
\hline كايا & .199 & $\cdot / V G$ & $\cdot / \Delta V$ & $\cdot 1 \Delta \Delta$ & $\cdot / \& \Lambda$ & .109 & . IVG & & & . IAT \\
\hline
\end{tabular}

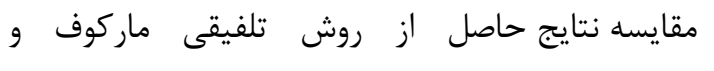

همانطور كه در جداول (rاو \&) نيز ديده مىشود،

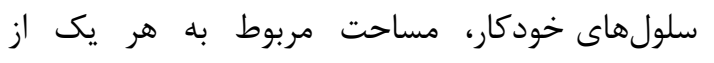

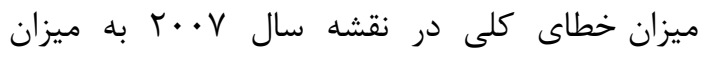

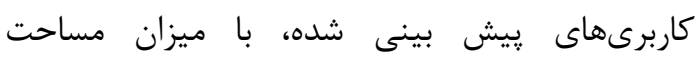

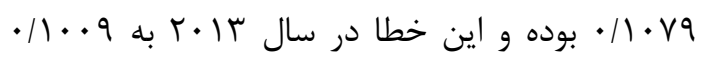

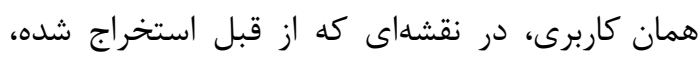

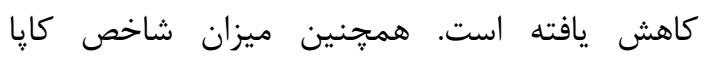

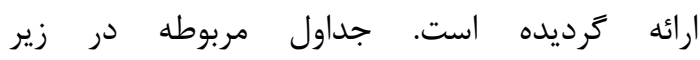

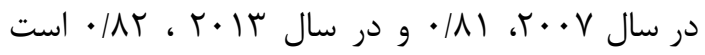

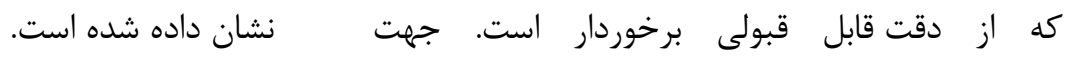

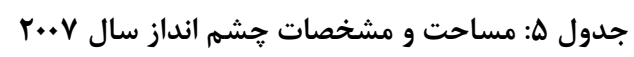

\begin{tabular}{|c|c|c|c|c|}
\hline رديف & كاربرى - ك - ك & مساحت (KM') & تفاضل جشم انداز و واقعيت & درصد تفاضل \\
\hline 1 & آب & rq.r & $\cdot .1$ & سب \\
\hline t & شوره زار & TYN.T & VQ.V & If \\
\hline r & شهرى & 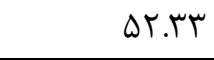 & V.rq & $-r q$ \\
\hline c & كشت ديم & rTr人.qA & $-\Delta 99 . \Delta$ & 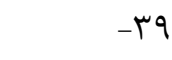 \\
\hline$\Delta$ & كشت آبى & 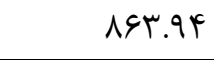 & $-\mu \boldsymbol{Y} \cdot \Lambda$ & 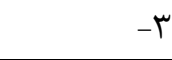 \\
\hline 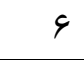 & باغ & $r Q \cdot . t t$ & $-\Lambda \cdot \cdot \vee$ & $\wedge$ \\
\hline V & 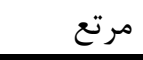 & 1.491 .99 & 190.1 & سץ \\
\hline
\end{tabular}

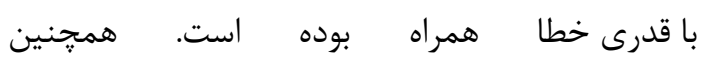

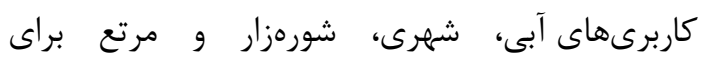

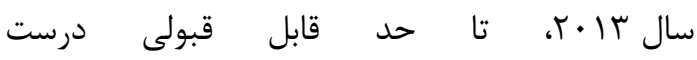

براى سال V • . F كاربرىهاى آبى، شهرى، باغ و مرتع

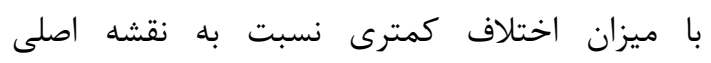

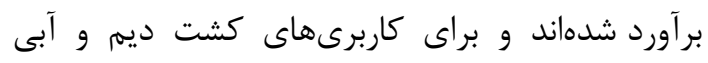
به دليل نحوه يراكنش و برديكى اين دو بـ به هم، 


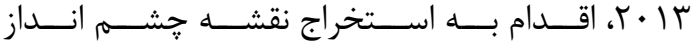

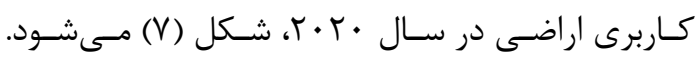
مساحت كاربرىهاى مختلف و همجنين ميزان تغييرات

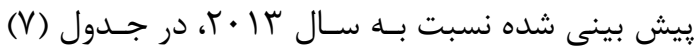

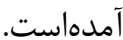

بهدست آمده است درصورتى كه كشت ديم و آبى مانند سال V • • با ميزان خطاى كمتر همراه بودهاند.

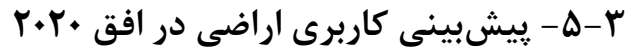
يس از ارزيابىهـاى فـوق و حصـول اطمينـان از نحـوه كاركرد مدل، با استفاده از نقشـهـ كـاربرى اراضى سرى سـال

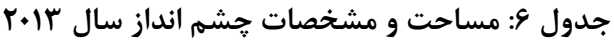

\begin{tabular}{|c|c|c|c|c|}
\hline رديف & كاربرى - ك & مساحت (KMㄹ) & تفاضل جشم انداز و واقعيت & درصد تفاضل \\
\hline 1 & آب & $\Delta 9 . V 9$ & $-|r . f|$ & $-r)$ \\
\hline r & شوره زار & IVF.tY & $-\tau \cdot . \varphi$ & -11 \\
\hline r & 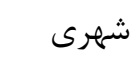 & QT.TV & $-\Lambda . \cdot 1$ & -10 \\
\hline f & 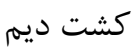 & r\$90.09 & rVq.19 & If \\
\hline$\Delta$ & كشت آبى & Trm & $r \cdot 9.9$ & IV \\
\hline 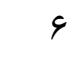 & باغ & MEF.D & $99 . \mathrm{r \Delta}$ & 19 \\
\hline v & 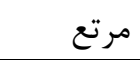 & $q \uparrow 1 \cdot . g r$ & -914.49 & -9 \\
\hline
\end{tabular}

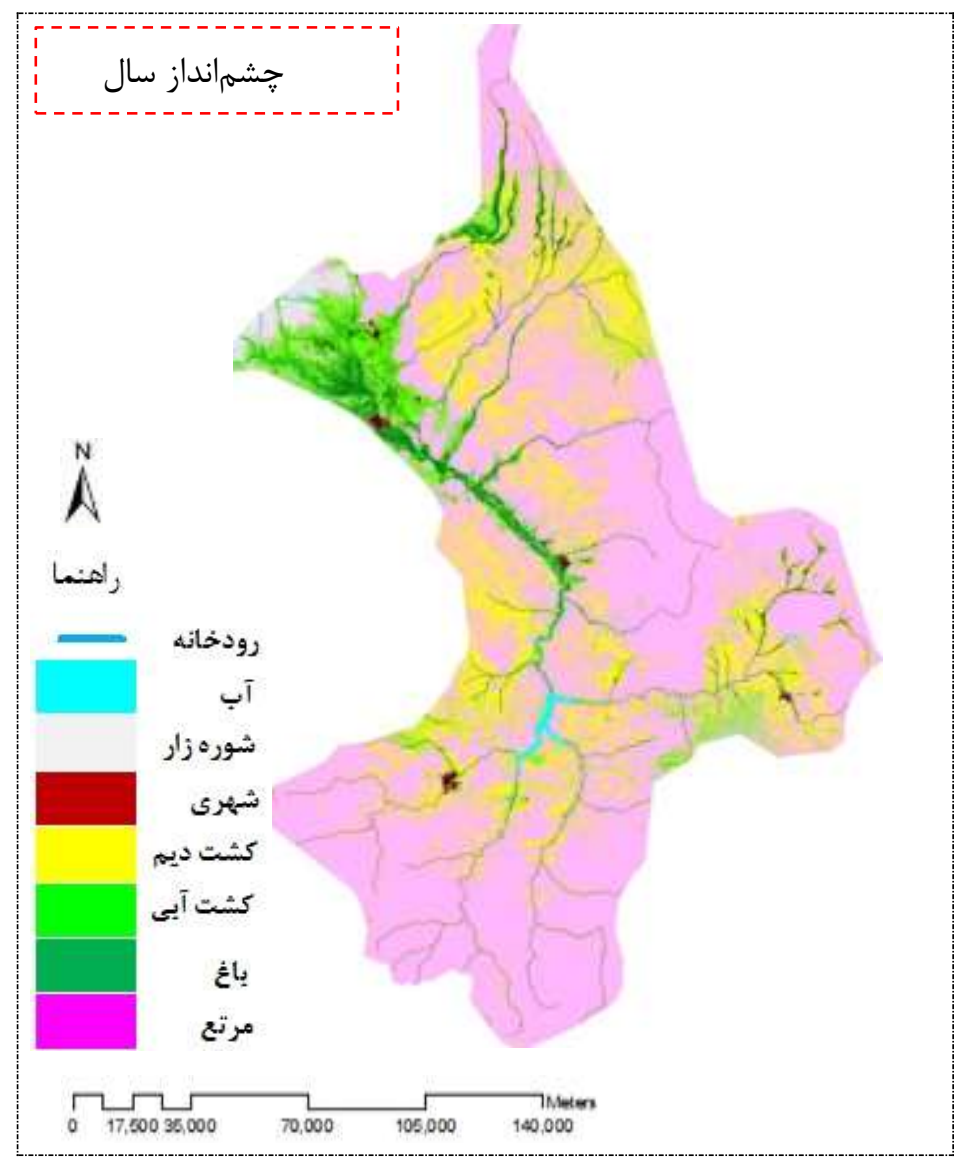

شكل Y: نقشه حشم انداز استخراج شده براى سال .r.r 


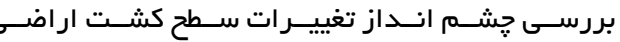

غلامعباس سهولى، مجيد دلاور"، محسن قمرى اصل

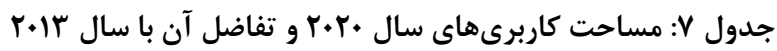

\begin{tabular}{|c|c|c|c|c|}
\hline رديف & كاربرى & مجموع مساحت (كيلومتر مربع) & تفاضل •r+r و rا+r & درصد تفاضل \\
\hline 1 & 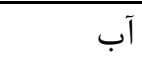 & VD.Vq & $9 . \Delta \Delta$ & $1 / 9$ \\
\hline$r$ & شوره زار & $\mid g F .+F$ & 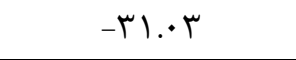 & -11 \\
\hline r & شهرى & GI.Iر & $\because 9$ & .11 \\
\hline f & كشت ديم & $r \Delta r \cdot I \varphi$ & TYF.EG & $\Lambda / \Lambda$ \\
\hline$\Delta$ & كشت آبى & 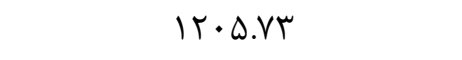 & IVD.VV & $\mid r / 0$ \\
\hline 4 & باغ & rVD.9l & qV.VG & rq \\
\hline V & 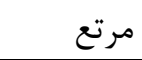 & $१ \Delta \Delta । . \wedge \mathrm{V}$ & -FVT.rd & $-\varphi / q$ \\
\hline
\end{tabular}

به مراتع افزوده شده است اما در دوره دوم اراضى تحست

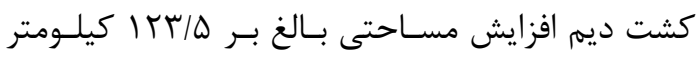

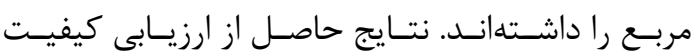

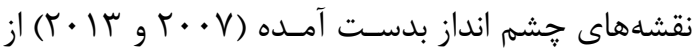

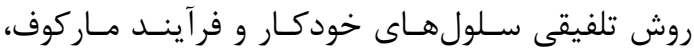

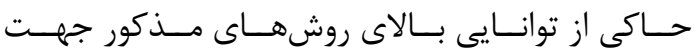

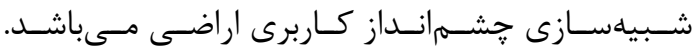

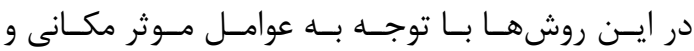

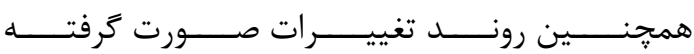
در دو تاريخ متوالى، جشهمانداز كاربرىها استخراج شـده

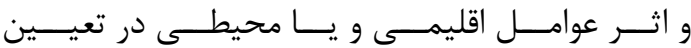

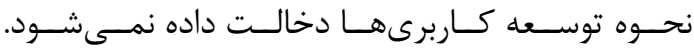

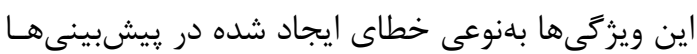
را توجيه يذير ساختهاند.

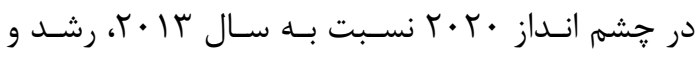

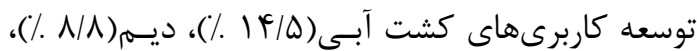

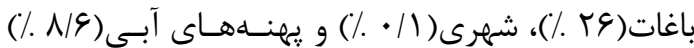

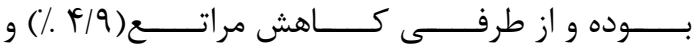

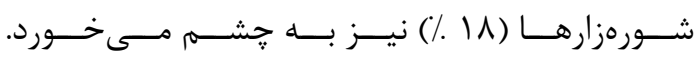
تغييرات يِشبينى شده ناشى از توسـعه منطقـه مـورد

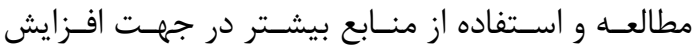
سطح زير كشت مىباشد.
طبق جدول (V) و پيش بينى انجام شده، رشد و توسعه اراضى كشاورزى اعم از كشت ديم، كشت آبى و

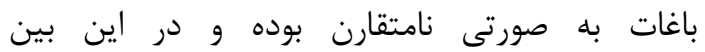

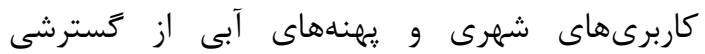

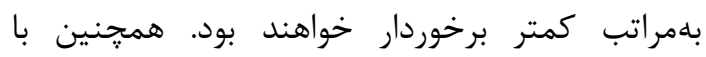

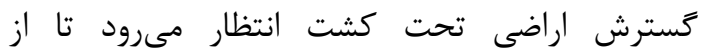
سطح اراضى مرتعى منطقه كاسته شود. اين ميزان

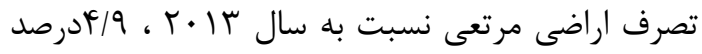

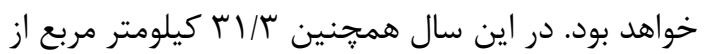

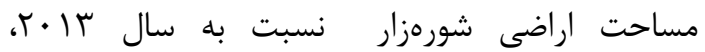
كاسته مىشود.

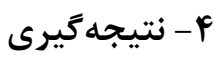
يس از ارزيابى تغييرات ايجاد شده در طـول سـالهـاى

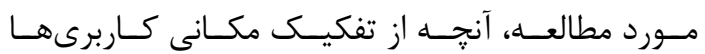

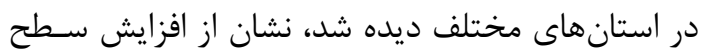

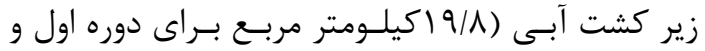

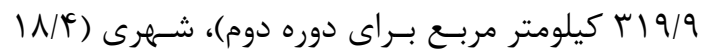

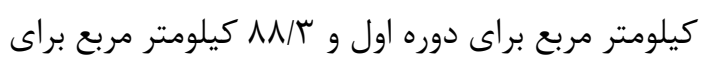
دوره دوم) و همجنين باغات (YI/Y كيلومتر مربع بـراى دوره اول و

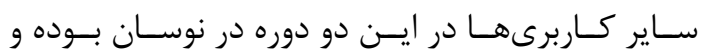
به مراتع موجود در منطقه اضافه و يا از آن كم شدهانـد.

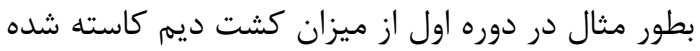

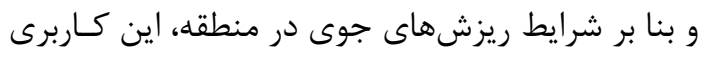


[1] A. Bronstert, D. Niehoff, and G. Bürger, “ Effects of climate and land - use change on storm runoff generation: present knowledge and modelling capabilities" , Hydrological Processes, 16(2), 509-529, 2002.

[2] B. Ott, and S. Uhlenbrook, "Quantifying the impact of land-use changes at the event and seasonal time scale using a processorientated catchment model", Hydrol Earth Syst Sci, 8, 62-78, 2004.

[3] D. Kaimowitz, and A. Angelsen, "Economic models of tropical deforestation", a review. Cifor, 1998.

[4] T. Wrbka, K. H. Erb, N. B. Schulz, J. Peterseil, C. Hahn, and H. Haberl, "Linking pattern and process in cultural landscapes. An empirical study based on spatially explicit indicators", Land use policy, 21(3), 289-306, 2004.

[5] A. Bahremand, F. Smedt, J. Corluy, Y. Liu, J. Porov, L. Velcick, and E. Kunikova, "Application of wetSpa model for assessing land use impacts on floods in the MargecanyHornad watershed, Slovakia", Water Science \& Technology , 53(10), 37 45, 2006.

[6] C. McColl, and G. Aggett, "Land-use forecasting and hydrologic model integration for improved land-use decision support", Journal of environmental management, 84(4), 494-512, 2007.

[7] N. Stephenne, and E. F. Lambin, “A dynamic simulation model of land-use changes in Sudano-sahelian countries of Africa (SALU)", Agriculture, ecosystems \& environment, 85(1), 145-161, 2001.

[8] S. Goldavi, "Comparision of logistic regression and Geomod in land cover change modeling and vegetation and effect of change on water (case study: Gorgan)", Doctoral dissertation, M. Sc thesis. Department of Environment, Gorgan University of Agricultural Sciences and Natural Resources, 2011.
[9] H. Memarian, S. K. Balasundram, K. C. Abbaspour, J. B. Talib, C. T. Boon Sung, and A. M. Sood, "SWAT-based hydrological modelling of tropical land-use scenarios", Hydrological Sciences Journal, 59(10), 1808-1829, 2014.

[10] M. T. C. Olmedo, R. G. Pontius, M. Paegelow, and J. F. Mas, "Comparison of simulation models in terms of quantity and allocation of land change", Environmental Modelling \& Software, 69, 214-221, 2015.

[11] H. Ahmadzadeh, "Evaluating the efficiency of agricultural water use SWAT model (case study: Zarineh rood)", M. Sc thesis, Tarbiat Modares University, 2013.

[12] H. Briassoulis, Analysis of changes in land use patterns, Tehran: Azarakhsh, 2000.

[13] S. A. Sisson, Y. Fan, and M. M. Tanaka, "Sequential monte carlo without likelihoods", Proceedings of the National Academy of Sciences, 104(6), 1760-1765, 2007.

[14] H. Balzter, "Markov chain models for vegetation dynamics", Ecological Modelling, 126(2), 139-154, 2000.

[15] D. G. Brown, B. C. Pijanowski, and J. D. Duh, "Modeling the relationships between land use and land cover on private lands in the Upper Midwest, USA", Journal of Environmental Management, 59(4), 247263, 2000.

[16] W. A. Clark, "Markov chain analysis in geography: an application to the movement of rental housing areas", Annals of the Association of American Geographers, 55(2), 351-359, 1965

[17] D. Mitsova, W. Shuster, and X. Wang, “A cellular automata model of land cover change to integrate urban growth with open space conservation", Landscape and Urban Planning, 99(2), 141-153, 2011.

[18] R. White, G. Engelen, and I. Uljee, "The use of constrained cellular automata for high-resolution modelling of urban land-use 


\section{بررسـى هشــم انــداز تغييــرات ســطح كشــت اراضـى...}

غلامعباس سهولى، مجيد دلاور"، محسن قمرى اصل

dynamics", Environment and planning, B, 24, 323-344, 1997.

[19] R. Rezazadeh, and M. Mirahmadi, “A cellular automaton, a new urban growth modeling", Journal of Technology Education, 4(1), 47-55, 2011.

[20] A. N. Pettitt, “A Non-parametric Approch to the Change-point Problem", Appl. Statist, 28, 126-135, 1979.

[21] P. Gao, X. M. Mu, F. Wang, and R. Li, "Changes in streamflow and sediment discharge and the response to the human activities in the middle reaches of the Yellow River", Hydrol. Earth. Syst. Sci, 15, 1-10, 2011.

[22] M. Ghodusi, "The effects of changing patterns of rainfall, land use and exploitation of Aji Chay Dam and its catchment hydrology pump on Urmia Lake", M. Sc thesis, Tarbiat Modares University, 2014.

[23] N. S. Pannu, and R. J. Read, "Improved structure refinement through maximum likelihood", Acta Crystallographica Section A: Foundations of Crystallography, 52(5), 659-668, 1996.

[24] M. A. Zare Chahooki, L. Khalasi Ahvazi, and H. Azar Nivand, "Plant species distribution modeling based on soil and topographical factors using logistic regression method in Semnan rangeland East", Iranian Journal of Natural Resources, 67(1), 45-59, 2015. 



\title{
Evaluation of landscape changes in Horizon 2020 cultivation of agricultural land in the basin Zarineh using a combination Markov and cellular automation
}

\author{
Gholam Abbas Sohooli $^{1}$, Majid Delavar ${ }^{* 2}$, Mohsen Ghamary Asl ${ }^{3}$
}

1- MSc. Student, Tarbiat Modares University

2- Assistant Professor, Tarbiat Modares University

3- PhD of Civil Eng., Khajeh Nasiroddin Tusi University

\begin{abstract}
Cultivation of agricultural land in the basin Zarineh has changed over the years and as one of the main reasons for reducing the inflow to Lake Urmia has been raised. Due to the possible development, Estimation of prospects of changes in the basin can play in key role in taking effective decisions and provide guidelines for dealing with the environmental crisis Lake Urmia is facing with. In this study has been tried to extract and assess the historical changes in land use in the Zarineh basin using satellite images and a projection of the future land use changes has been provided. In this regard, a combined of CA-MARKOV method was used. Results show that between 2000 and 2013, on average, most of changes lean toward increase in land use, such as irrigated agriculture (40\%) and gardens $(57 \%)$ and also to reduce pasture land $(5 \%)$ and dryland farming (10\%). This trend has also been observing for horizon of year 2020.
\end{abstract}

Key words: Land use, Prediction, Cellular automata, Zarrineh Roud. 